\title{
Resource Provider
}

National Cancer Institute

\section{Source}

National Cancer Institute. Resource Provider. NCI Thesaurus. Code C93449.

An org anization or person that typically provides financial or other resources for the conduct of research. 